\title{
Cell Growth Regulated by Syndecan-1 in Human Liposarcoma
}

\author{
Shinji Tsukamoto ${ }^{1,2}$, Keiji Shimada ${ }^{2}$, Kanya Honoki ${ }^{1}$, Akira Kido ${ }^{1}$, Manabu Akahane ${ }^{3,}$ Yasuhito Tanaka ${ }^{1}$, \\ Noboru Konishi ${ }^{2}$ \\ ${ }^{1}$ Department of Orthopaedic Surgery, Nara Medical University, Nara, Japan \\ ${ }^{2}$ Department of Pathology, Nara Medical University, Nara, Japan \\ ${ }^{3}$ Department of Public Health, Health Management and Policy, Nara Medical University, Nara, Japan \\ Correspondence: Shinji Tsukamoto, Department of Orthopaedic surgery, Nara Medical University, 840 Shijo-cho, \\ Kashihara, Nara 634-8521, Japan. Tel: +81-744-22-3051. E-mail: shinji104@mail.goo.ne.jp
}

Received: March 16, 2015 Accepted: April 11, 2015 Online Published: April 24, 2015

doi:10.5539/cco.v4n1p58 URL: http://dx.doi.org/10.5539/cco.v4n1p58

\begin{abstract}
Background: The heparan sulfate proteoglycan, syndecan-1 (also known as CD138), is associated with cell proliferation, adhesion, and migration in various types of human malignancies. The role of syndecan-1 in soft tissue tumors is unknown; therefore we examined whether syndecan-1 plays a role in human liposarcoma.

Materials and Methods: We performed immunohistochemical analyses of syndecan-1 in 42 liposarcoma cases, including 21 myxoid liposarcoma cases. Recurrence-free survival was estimated by the Kaplan-Meire method. We examined the association between apoptosis and syndecan-1 gene silencing in a human liposarcoma cell line.

Results: The proportion of syndecan-1 positive cells $(\geq 10 \%)$ was significantly associated with unfavorable recurrence-free survival in myxoid liposarcoma patients. There were no significant associations between syndecan-1 expression and prognosis in the other subtypes of liposarcoma. Knockdown of syndecan-1 induced apoptosis and suppression of cell growth in vitro.
\end{abstract}

Conclusion: Syndecan-1 could be a novel prognostic factor for myxoid liposarcoma recurrence and a new therapeutic target for human myxoid liposarcoma.

Keywords: apoptosis, CD138, liposarcoma, sarcoma, syndecan-1

\section{Introduction}

Liposarcoma is the most common soft tissue sarcoma, accounting for at least $20 \%$ of all sarcomas in adults (Mack, 1995). Histologically, liposarcomas can be divided into three categories: atypical lipomatous tumor/well-differentiated liposarcoma/dedifferentiated liposarcomas, myxoid liposarcomas, and pleomorphic liposarcomas. The most important prognostic factor of atypical lipomatous tumor and dedifferentiated liposarcoma is anatomic location (Fletcher, Bridge, Hogendoorn, \& Mertens, 2013). For localized myxoid liposarcoma, high histological grade (often defined as $>5 \%$ round cell component), presence of necrosis, and alterations in TP53 and CDKN2A are predictors of unfavorable outcome (Fletcher et al., 2013). For pleomorphic liposarcoma, central location, tumor depth, size and mitotic index have been associated with a worse prognosis (Fletcher et al., 2013). The recurrence rate for atypical lipomatous tumors, dedifferentiated liposarcomas, myxoid liposarcomas and pleomorphic liposarcomas are 63,14,41, and 43\%, respectively; associated mortalities for these tumors are 11, 31, 28 and 35\%, respectively (Weiss \& Rao, 1992; Kilpatrick, Doyon, Choong, Sim, \& Nascimento, 1996; Henricks, Chu, Goldblum, \& Weiss, 1997; Gebhard et al., 2002).

Surgery serves as the sole therapy for localized liposarcomas. Generally, liposarcomas are known to be a relatively chemoresistant tumor, with the exception of the myxoid variant. Conventional chemotherapy with doxorubicin and ifosfamide is the first-line treatment for liposarcomas. Other active cytotoxic agents include gemcitabine, docetaxel and the marine-derived compound trabectedin (Kollár \& Benson, 2014). Moreover, liposarcomas, excluding the myxoid variant, are highly resistant to radiotherapy. Liposarcoma patients with metastases or poor response to chemotherapy have worse prognosis; therefore a new therapeutic drug is required.

Syndecan-1, also known as CD138, is a member of a family containing four mammalian heparan sulfate proteoglycans. Syndecan-1 is highly expressed in many types of normal epithelial cells and some of their malignant counterparts. It plays important roles in cell growth, adhesion, migration, epithelial morphogenesis, 
and angiogenesis (Bernifield et al., 1999). In hematologic disorders, syndecan-1 expression marks hematopoietic cells with plasmacytic differentiation, as well as other B-cell-lineage hematopoietic neoplasms such as immunoblastic diffuse large B-cell lymphoma and marginal zone lymphoma (O'Connell, J. L. Pinkus, \& G. S. Pinkus, 2004). Syndecan-1 expression is dysregulated in many cancers, and its expression is associated with prognosis in squamous cell carcinomas of the head and neck (Inki, Joensuu, Grénman, Klemi, \& Jalkanen, 1994; Anttonen, Kajanti, Heikkila, Jalkanen, \& Joensuu, 1999), colorectal, pancreatic and prostate adenocarcinoma (Day et al., 1999; Conejo et al., 2000; Zellweger et al., 2003), breast carcinoma (Loussouarn et al., 2008), renal cell carcinoma (Gökden et al., 2006), hepatocellular carcinoma (Matsumoto et al., 1997), and malignant mesothelioma (Kumar-Singh et al., 1998). We previously reported increased levels of syndecan-1 expression in prostate adenocarcinoma and urothelial carcinoma, suggesting that increased syndecan-1 expression contributes to cancer progression (Shimada et al., 2009; Shimada et al., 2010). Syndecan-1 is not readily detected by immunohistochemistry in differentiated benign mesenchymal cells or tumors. Low expression levels of syndecan-1 are produced by cultured endothelial cells (Elenius \& Jalkanen, 1994). Although expression has been reported in some other soft tissue tumor cells (O'Connell et al., 2004; Orosz \& Kopper, 2001), the role of syndecan-1 in liposarcomas remains unknown.

We conducted a clinicopathologic and prognostic analysis of syndecan-1 expression in 42 liposarcoma specimens and their benign counterparts. We examined the roles of syndecan-1 in liposarcoma by in vitro studies. Syndecan-1 overexpression was correlated to a poor prognostic factor for recurrence-free survival in myxoid liposarcoma patients. In addition, syndecan-1 silencing through siRNA transfection effectively induced cellular apoptosis and growth suppression of liposarcoma cells in vitro. We found that cell growth and clinical recurrence might be enhanced by syndecan-1 in human myxoid liposarcoma.

\section{Materials and Methods}

\subsection{Cell Culture}

The human liposarcoma cell line SW872 was purchased from the American Type Culture Collection (Rockville, MD, USA). Cells were maintained in Leibovitz's L- 15 medium with $12 \%$ fetal bovine serum at $37{ }^{\circ} \mathrm{C} / 5 \% \mathrm{CO}_{2}$.

\subsection{RNA Silencing of Syndecan-1}

We seeded $8 \times 10^{4} \mathrm{SW} 872$ cells per well in six-well culture dishes. Cells were transfected with $132 \mathrm{nM}$ short interfering RNAs (siRNAs) specific for syndecan-1 (Qiagen, Venlo, Netherlands). Transfections were carried out using Lipofectamine RNAiMAX (Life Technologies, Foster City, CA, USA) in accordance with the manufacturer's protocol. The syndecan-1 siRNA sequence (5'-TCC GAC TGC TTT GGA CCT AAA-3') was designed following selection of appropriate DNA target sequences.

\subsection{Extraction of Total RNA and Reverse-Transcription Polymerase Chain Reaction (RT-PCR) Assays}

We extracted total RNA from samples using an RNeasy Mini kit (Qiagen). We synthesized cDNA from $1 \mu \mathrm{g}$ of purified total RNA using PrimeScript RT Master Mix (Perfect Real Time; Takara, Shiga, Japan) and SYBR Premix Ex Taq II (TliRNaseH Plus; Takara). Each reaction was subjected to thermal cycling at $95{ }^{\circ} \mathrm{C}$ for $30 \mathrm{~s}$ and $55-63{ }^{\circ} \mathrm{C}$ for $30 \mathrm{~s}$ over $35-45$ cycles. The amount of actin mRNA was used to standardize the quantity of syndecan-1 mRNA. Primers are as follows: actin sense, 5'-ATGGGTCAGAAGGATTCCTATGT-3' and actin antisense, 5'-GAAGGTCTCAAACATGATCTGGG-3'; and syndecan-1 sense, 5'-GGCTGTAGTCCTGCCAGAAG-3' and antisense, 5'-GTTGAGGCCTGATGAGTGGT-3'.

\subsection{Terminal Deoxynucleotidyl Transferase-Mediated dUTP Nick end Labeling (TUNEL) Assays}

DNA cleavage, a characteristic of apoptosis, was detected using the TUNEL assay (Apop Tag Plus Peroxidase In situ Apoptosis Detection Kit; Millipore, Temecula, CA, USA). After siRNA transfection, cells were washed with phosphate-buffered saline once for 3 min and fixed with CytoRich Red (Becton-Dickinson, Franklin Lakes, NJ, USA) at room temperature for $30 \mathrm{~min}$. The fixed cells were washed with distilled water once for $3 \mathrm{~min}$, deposited on a slide, further fixed in $95 \%$ ethanol, and stained with the above kit. At least 600 cells from three different fields of view were examined from each experiment. Cell death was expressed as the percentage of TUNEL-positive cells.

\subsection{Cell Proliferation Assays}

Cells were stimulated with various reagents and then treated with 3-(4,5-dimethylthiazol-2-yl)-5(3-carboxymethoxyphenyl)-2-(4-sulphonyl)-2H-tetrazolium (Promega, Tokyo, Japan), a tetrazolium salt. After a $2 \mathrm{~h}$ incubation, the absorbance at $490 \mathrm{~nm}$ was determined with a microplate reader. Cell viability was expressed as the mean absorbance ratio ( \pm standard deviations) following transfection with control RNA and syndecan-1 
siRNA. All experiments were performed in triplicate.

\subsection{Tissue Samples}

After obtaining approval from our institutional review board, we searched the surgical pathology database of our institution for the period July 1984 to June 2012. As shown in Table 1, we examined 42 cases of liposarcoma (14 atypical lipomatous tumors, six dedifferentiated liposarcomas, 21 myxoid liposarcomas, and one pleomorphic liposarcoma), 34 cases of lipoma and 20 cases of normal adipose tissue. The liposarcoma specimens included 27 primary tumors and 15 local recurrent or distant metastatic tumors. Only myxoid liposarcoma specimens included 10 primary, 10 local recurrent and 1 distant metastatic tumors. Diagnoses for all of these tumors were made according to the latest edition of the World Health Organization classification scheme (Fletcher et al., 2013). In regard to myxoid liposarcoma, fluorescence in situ hybridization analysis of the DNA damage-inducible transcript 3 (DDIT3) and fused in sarcoma (FUS) loci was performed in three of the 21 examined cases. We found that $3 / 3$ cases showed both DDIT3 and FUS gene rearrangements. Clinical details and follow-up information were obtained by reviewing medical charts. The clinicopathologic characteristics of myxoid liposarcoma are summarized in Table 2. The 21 cases included 11 men and 10 women with an age range of 28-83 years (median, 52 years). Tumors were located in the extremities for 15 cases (thigh, 11; lower leg, three; forearm, one), in the trunk wall in five cases (buttock, three; abdominal wall, two), and in the retroperitoneum in one case. All primary tumors were treated with surgery, accompanied by adjuvant chemotherapy or irradiation in eight cases. For staging of the tumors, the latest American Joint Committee on Cancer (AJCC) staging system was used (Edge et al., 2010). The median follow-up period after surgery was 79 months (range, 5-244 months). Recurrence-free survival was defined as the interval from diagnosis to discovery of a local recurrence or the last follow-up examination.

\subsection{Immunohistochemistry}

Immunohistochemical staining for syndecan-1, Ki-67, MDM2 and p16 was performed. A previous study showed that cell surface syndecan-1 binds to hepatocyte growth factor (HGF) via heparan sulfate chains and promotes Met activation, leading to myeloma cell growth and survival (Teng, Aquino, \& Park, 2012). Thus, membranous expression of syndecan-1 was considered a positive signal. The levels of syndecan-1 and Ki67 immunostaining were graded according to the proportion of positively stained cells (negative, $<10 \%$; positive, $\geq 10 \%$ ). The levels of MDM2 and p16 immunostaining were graded according to the proportion of positively stained cells (negative, $<1 \%$; positive, $\geq 1 \%$ ). Tumor tissue from each case was fixed in $10 \%$ neutral-buffered formalin and embedded in paraffin. Specimens were cut at $4 \mu \mathrm{m}$ intervals and mounted for immunohistochemical analysis and histopathological analysis by conventional hematoxylin and eosin (HE) staining. The HE-stained sections served as a guide for immunohistochemical analyses. After deparaffinization in xylene and sequential hydration in 100 and $95 \%$ ethanol, sections were heated $120^{\circ} \mathrm{C}$ for $10 \mathrm{~min}$ in $10 \mathrm{mM}$ sodium citrate buffer (pH 6.0) and incubated with antibodies against syndecan-1 (1:20 dilution; clone MI15; Thermo Fisher Scientific, Rockford, IL, USA), Ki-67 (1:1; clone SP6; Nichirei, Tokyo, Japan), MDM2 (1:250; clone IF2; Life Technologies) and p16 (1:50; clone JC8; Santa Cruz Biotechnology Inc., Santa Cruz, CA, USA). Immunoreactivity was visualized using a Histofine SAB-PO kit with diaminobenzidine as the chromogen (Nichirei), and hematoxylin counterstaining.

\subsection{Statistical Analysis}

A $t$-test was used for comparison of means between two independent samples. Levene test was applied to verify the homoscedasticity. The univariate relationship between each clinicopathological variable and syndecan-1 expression was evaluated using the chi-squared test or Fisher's exact test. Recurrence-free survival was analyzed for 21 myxoid liposarcoma patients. Recurrence-free survival was estimated by the Kaplan-Meier method. The log-rank test was used to evaluate the differences between survival curves. These analyses were performed with IBM SPSS ver. 20.0 (IBM Co., Armonk, NY, USA). A p-value less than 0.05 was considered statistically significant for all tests.

\section{Results}

\subsection{Syndecan-1 Immunostaining and Prognostic Significance}

As a pilot study, we previously examined syndecan-1 expression by immunohistochemistry in 158 soft tissue sarcomas and found significant results in lipomatous tumors. Syndecan-1 expression was observed in $12 \%$ of all liposarcomas but not in lipomas and normal adipose tissue (Table 1). The results of MDM2 and p16 immunostaining are also shown in Table 1. 
Table 1. Summary of syndecan-1, MDM2 and p16 immunoreactivity

\begin{tabular}{lllll}
\hline Histology & No of cases & $\begin{array}{c}\text { No.(\%) of syndecan-1 } \\
\text { positive cases }\end{array}$ & $\begin{array}{c}\text { No.(\%) of MDM2 } \\
\text { positive cases }\end{array}$ & $\begin{array}{c}\text { No.(\%) of p16 } \\
\text { positive cases }\end{array}$ \\
\hline liposarcoma & 42 & $5(12)$ & & $12(86)$ \\
atypical lipomatous tumor & 14 & $2(14)$ & $14(100)$ & $6(100)$ \\
dedifferentiated liposarcoma & 6 & $0(0)$ & $4(67)$ & $7(33)$ \\
myxoid liposarcoma & 21 & $2(10)$ & $0(0)$ & $1(100)$ \\
pleomorphic liposarcoma & 1 & $1(100)$ & $0(0)$ & $2(6)$ \\
\hline lipoma & 34 & $0(0)$ & $7(21)$ & $0(0)$ \\
\hline nomal adipose tissue & 20 & $0(0)$ & $0(0)$ &
\end{tabular}

No significant association between syndecan-1 expression and prognosis in each subtype of liposarcoma was detected (data not shown), except in myxoid liposarcomas. Therefore, we summarized the correlation between syndecan-1 immunopositivity and myxoid liposarcoma clinicopathologic factors in Table 2.

Table 2. Association between clinicopathologic variables and syndecan-1 expression in myxoid liposarcoma

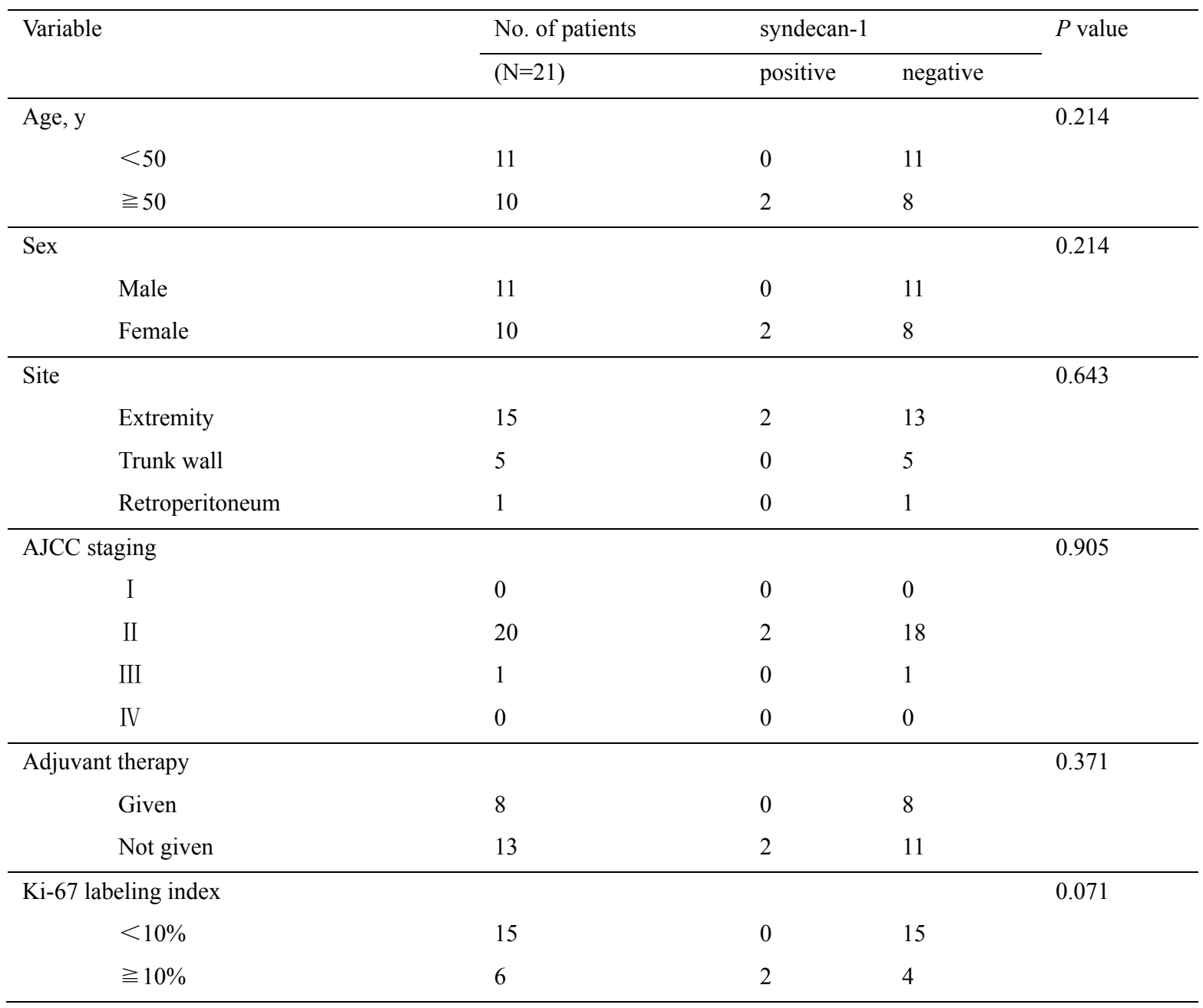

Immunohistochemistry of myxoid liposarcoma showed that syndecan-1 was expressed in both the nucleus and the cell membrane (Figure 1). 


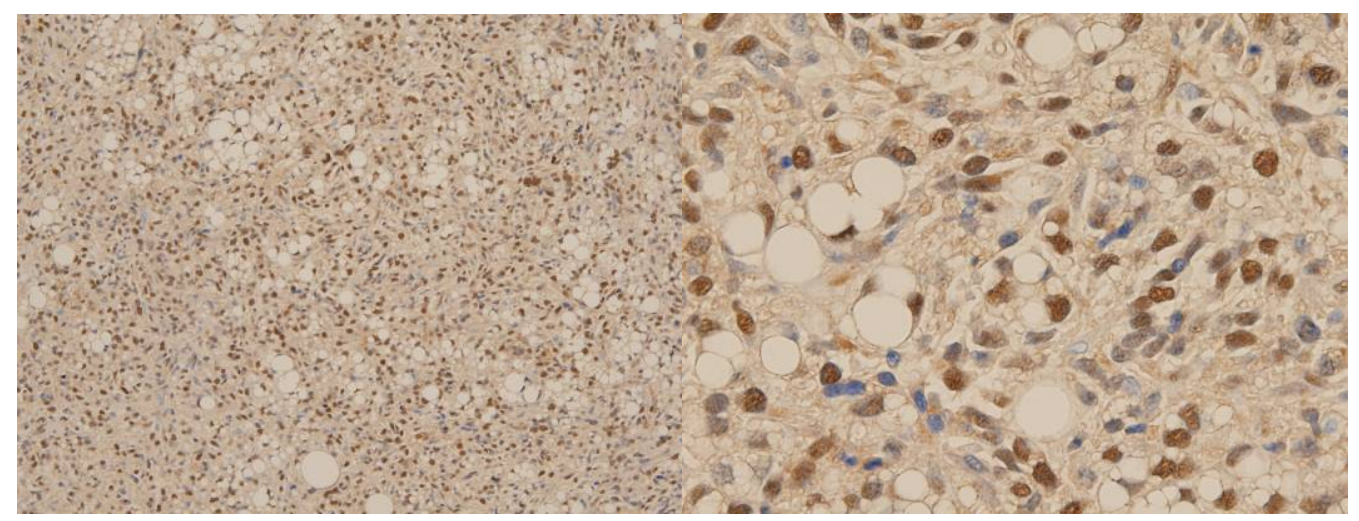

A

B

Figure 1. Myxoid liposarcoma. Immunohistochemical analysis showed that syndecan-1 is expressed in both the nucleus and the cell membrane $(\mathrm{A}, \times 100 ; \mathrm{B}, \times 400)$.

The two cases of syndecan-1 positive myxoid liposarcoma were primary and local recurrent tumors. Positive syndecan-1 staining showed a significant association with unfavorable recurrence-free survival of myxoid liposarcoma patients by a univariate prognostic analysis $(p=0.023$; Table 3; Figure 2). Male was also associated with poor prognosis $(\mathrm{p}=0.04$; Table 3$)$. We also investigated the relationships between percentage of syndecan-1 positive tumor cells and overall or metastatic-free survival in myxoid liposarcoma patients using the Kaplan-Meier method. We found no significant associations between percentage of syndecan-1 positive tumor cells and outcomes (data not shown).

Table 3. Univarite analysis for Recurrence-Free Survival in myxoid liposarcoma patients

\begin{tabular}{|c|c|c|c|}
\hline Variable & No. of patients & $\begin{array}{l}\text { 5-y recurrence-free } \\
\text { survival }(\%)\end{array}$ & $P$ value \\
\hline Age, $y$ & & & 0.441 \\
\hline$<50$ & 11 & 71.6 & \\
\hline$\geqq 50$ & 10 & 43.8 & \\
\hline Sex & & & 0.04 \\
\hline Male & 11 & 85.7 & \\
\hline Female & 10 & 33.3 & \\
\hline Site & & & 0.685 \\
\hline Extremity & 15 & 65.8 & \\
\hline Trunk & 6 & 50 & \\
\hline AJCC staging & & & 0.438 \\
\hline $\mathrm{I}+\mathrm{II}$ & 20 & 100 & \\
\hline $\mathrm{III}+\mathrm{IV}$ & 1 & 54.9 & \\
\hline Adjuvant therapy & & & 0.508 \\
\hline Given & 8 & 72.9 & \\
\hline Not given & 13 & 51.1 & \\
\hline Ki-67 labeling index & & & 0.251 \\
\hline$<10 \%$ & 15 & 66.1 & \\
\hline$\geqq 10 \%$ & 6 & 40 & \\
\hline Syndecan-1 & & & 0.023 \\
\hline positive & 2 & 0 & \\
\hline negative & 19 & 65.3 & \\
\hline
\end{tabular}




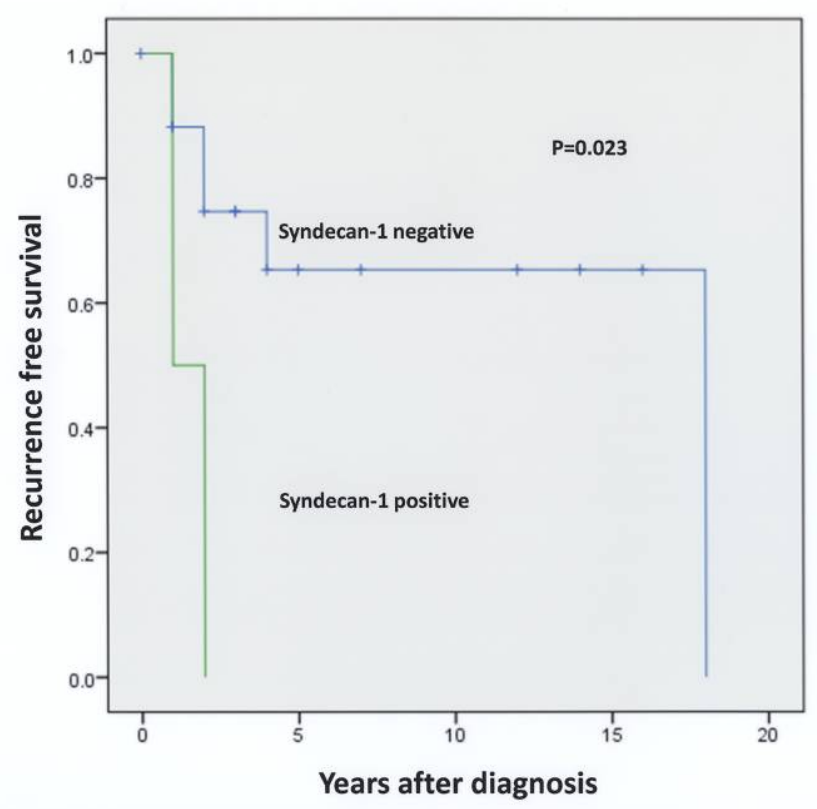

Figure 2. Kaplan-Meier analysis of recurrence-free survival in myxoid liposarcoma patients with syndecan-1 expression

\subsection{Syndecan-1 Silencing Induced Apoptosis}

Expression of syndecan-1 mRNAs was reduced by transfection with specific siRNAs (Figure 3A). Silencing of the syndecan-1 gene was confirmed by western blotting (data not shown). Cell growth was significantly suppressed $72 \mathrm{~h}$ after transfection with syndecan-1 siRNAs (Figure 3B). The proportion of apoptotic cells, as assessed by TUNEL assays, increased in response to syndecan-1 knockdown (control RNA vs. syndecan-1 siRNA, $0.58 \pm 0.015$ vs. $2.72 \pm 0.398 \%$; $=0.033$; Figure 3C).

$$
\text { (A) }
$$

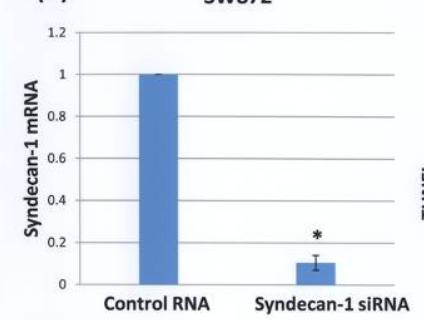

(B)



(C)
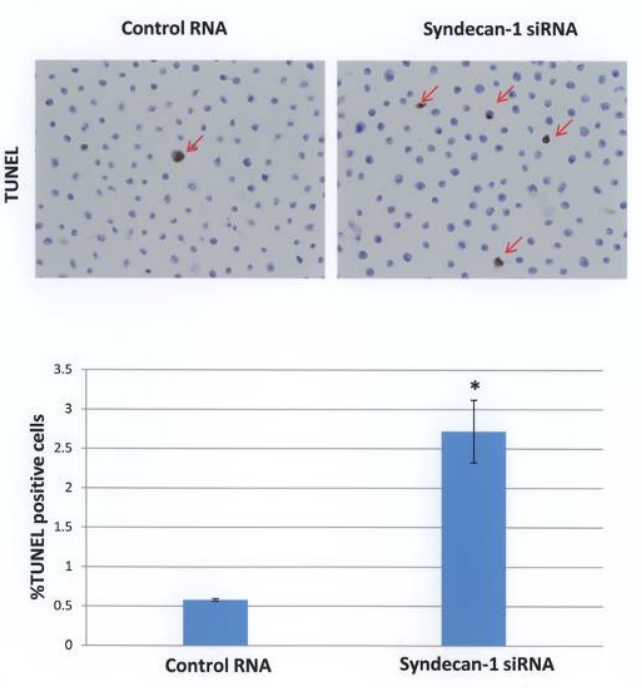

Figure 3. Downregulation of syndecan-1 induced apoptosis in human liposarcoma

A, SW872 cells were transfected with $132 \mathrm{nM}$ syndecan-1 siRNA or control RNA. Cells were cultured for a further $48 \mathrm{~h}$ after transfection, and expression of syndecan-1 mRNA was determined by RT-PCR. B, SW872 cells were cultivated for $72 \mathrm{~h}$ after control RNA or syndecan-1 siRNA transfection and cell growth rates were determined. C, SW872 cells were cultivated for $72 \mathrm{~h}$ after control RNA or syndecan-1 siRNA transfection and 
subjected to TUNEL assays. Each value is presented as the mean \pm SE. $* P<0.05$.

\section{Discussion}

In our study, prognostic analyses showed that syndecan-1 expression might be an unfavorable prognostic factor for recurrence-free survival in myxoid liposarcoma patients $(P<0.05)$. However, owing to the patient numbers, statistical power is weak and thus is a limitation of this study. Previous studies on the roles of syndecan- 1 during neoplastic transformation and progression of various human malignancies revealed various findings dependent on tumor type (Sanderson \& Borset, 2002). In squamous cell carcinomas of the head and neck (Inki et al., 1994; Anttonen et al., 1999), colorectal adenocarcinoma (Day et al., 1999), breast carcinoma (Loussouarn et al., 2008), renal cell carcinoma (Gökden et al., 2006), hepatocellular carcinoma (Matsumoto et al., 1997) and malignant mesothelioma (Kumar-Singh et al., 1998), downregulation of syndecan-1 expression was observed with tumor progression. In contrast, increased syndecan-1 expression was seen in pancreatic and prostate adenocarcinomas compared with their benign counterparts (Conejo et al., 2000; Zellweger et al., 2003). Thus, syndecan-1 might have varying effects on the progression of different tumor types. Limited data are available regarding the prognostic value of syndecan-1 expression in soft tissue sarcomas (O'Connell et al., 2004; Orosz et al., 2001). Our results suggest that syndecan-1 immunohistochemistry may help us to predict the risk of local recurrence of myxoid liposarcomas prior to clinical treatment.

In the present study, syndecan-1 knockdown suppressed cell growth through the induction of apoptosis in human liposarcoma cells. Syndecan-1 gene silencing induced growth arrest and apoptosis in myeloma cells. This could be because of diminished pro-survival signals as a result of reduced levels of cell surface heparan sulfate proteoglycan co-receptors for growth factor signaling (Khotskaya et al., 2009). This mechanism also applies to liposarcoma cells. Moreover, syndecan-1 synergizes with heparanase to promote myeloma bone disease by activating the HGF-Met-IL-11-RANKL signaling pathway (Teng et al., 2012). Therapy targeting the syndecan-1/heparanase axis can block the aggressive behavior of tumors, and could lead to new tumor therapies against drug-resistant cancers or sarcomas. Thus, our findings suggest that a therapy directly targeting syndecan-1 and heparanase inhibitors should be effective against myxoid liposarcomas.

In summary, our results show that syndecan-1 overexpression may be associated with unfavorable recurrence-free survival in myxoid liposarcoma patients. In addition, syndecan-1 may be essential for cell growth in liposarcoma in vitro. Therefore, syndecan-1 could represent a new molecular target and a useful clinicopathological marker in myxoid liposarcoma.

\section{Disclosure Statement}

The authors have no conflicts of interest to declare.

\section{References}

Anttonen, A., Kajanti, M., Heikkila, P., Jalkanen, M., \& Joensuu, H. (1999). Syndecan-1 expression has prognostic significance in head and neck carcinoma. $\mathrm{Br} J$ Cancer, 79(3-4), 558-564. http://dx.doi.org/10.1038/sj.bjc.6690088

Bernifield, M., Gotte, M., Park, P.W., Reizes, O., Fitzgerald, M.L., Lincecum, J., \& Zako, M. (1999). Functions of cell surface heparan sulfate proteoglycans. Annu Rev Biochem, 68, 729-777. http://dx.doi.org/10.1146/annurev.biochem.68.1.729

Conejo, J. R., Kleeff, J., Koliopanos, A., Matsuda, K., Zhu, Z. W., Goecke, H., ... Büchler, M. W. (2000). Syndecan-1 expression is up-regulated in pancreatic but not in other gastrointestinal cancers. Int $J$ Cancer, 88(1), 12-20. http://dx.doi.org/10.1002/1097-0215(20001001)88:1<12::AID-IJC3>3.0.CO;2-T

Day, R. M., Hao, X, Ilyas, M., Daszak, P., Talbot, I. C., \& Forbes, A. (1999). Changes in the expression of syndecan-1 in the colorectal adenoma-carcinoma sequence. Virchows Arch, 434(2), 121-125. http://dx.doi.org/10.1007/s004280050315

Edge, S. B., Byrd, D. R., Compton, C. C., Fritz, A. G., Greene, F. L., \& Trotti, A. (2010). AJCC cancer staging manual (7th, ed.). New York, Springer.

Elenius, K., \& Jalkanen, M. (1994). Function of the syndecans: a family of cell surface proteoglycans. J Cell Sci, 107, 2975-2982.

Fletcher, C. D. M., Bridge, J. A., Hogendoorn, P., \& Mertens, F. (2013). Adipocytic tumours, WHO Classification of Tumours of Soft Tissue and Bone (pp. 19-43). Lyon, IARC. 
Gebhard, S., Coindre, J. M., Michels, J. J., Terrier, P., Bertrand, G., Trassard, M., ... Picot, V. G. (2002). Pleomorphic liposarcoma: clinicopathologic, immunohistochemical, and follow-up analysis of 63 Cases: A study from the French Federation of Cancer Centers Sarcoma Group. Am J Surg Pathol, 26(5), 601-616.

Gökden, N., Greene, G.F., Bayer-Garner, I. B., Spencer, H. J., Sanderson, R. D., \& Gökden, M. (2006). Expression of CD138 (syndecan-1) in renal cell carcinoma is reduced with increasing nuclear grade. Appl Immunohistochem Mol Morphol, 14(2), 173-177.

Henricks, W. H., Chu, Y. C., Goldblum, J. R., \& Weiss, S. W. (1997). Dedifferentiated liposarcoma: a clinicopathological analysis of 155 cases with a proposal for an expanded definition of dedifferentiation. Am J Surg Pathol, 21(3), 271-281. http://dx.doi.org/10.1097/00000478-199703000-00002

Inki, P., Joensuu, H., Grénman, R., Klemi, P., \& Jalkanen, M. (1994). Association between syndecan-1 expression and clinical outcome in squamous cell carcinoma of the head and neck. $B r J$ Cancer, 70(2), 319-323. http://dx.doi.org/10.1038/bjc.1994.300

Khotskaya, Y. B., Dai, Y., Ritchie, J. P., MacLeod, V., Yang, Y., Zinn, K., Sanderson, R. D. (2009). Syndecan-1 is required for robust growth, vascularization, and metastasis of myeloma tumors in vivo. $J$ Biol Chem, 284(38), 26085-26095. http://dx.doi.org/10.1074/jbc.M109.018473

Kilpatrick, S. E., Doyon, J., Choong, P. F. M., Sim, F. H., \& Nascimento, A. G. (1996). The clinicopathologic spectrum of myxoid and round cell liposarcoma. Cancer, 77(8), 1450-1458. http://dx.doi.org/10.1002/(SICI)1097-0142(19960415)77:8<1450::AID-CNCR5>3.0.CO;2-G

Kollár, A., \& Benson, C. (2014). Current management options for liposarcoma and challenges for the future. Expert Rev Anticancer Ther, 14(3), 297-306. http://dx.doi.org/10.1586/14737140.2014.869173

Kumar-Singh, S., Jacobs, W., Dhaene, K., Weyn, B., Bogers, J., Weyler, J., \& Van-Marck, E. (1998). Syndecan-1 expression in malignant mesothelioma: correlation with cell differentiation, WT1 expression, and clinical $\begin{array}{lllll}\text { outcome. } & \mathrm{J} & \text { Pathol, 300-305. }\end{array}$ http://dx.doi.org/10.1002/(SICI)1096-9896(1998110)186:3<300::AID-PATH180>3.0.CO;2-Q

Loussouarn, D., Campion, L., Sagan, C., Frenel, J. S., Dravet, F., Classe, J. M., ... Campone, M. (2008). Prognostic impact of syndecan-1 expression in invasive ductal breast carcinoma. Br J Cancer, 98(12), 1993-1998. http://dx.doi.org/10.1038/sj.bjc.6604400

Mack, T. (1995). Sarcomas and other malignancies of soft-tissue, retroperitoneum, peritoneum, pleura, heart, mediastinum, and spleen. Cancer, http://dx.doi.org/10.1002/1097-0142(19950101)75:1+<211::AID-CNCR2820751309>3.0.CO;2-X

Matsumoto, A., Ono, M., Fujimoto, Y., Gallo, R. L., Bernfield, M., \& Kohgo, Y. (1997). Reduced expression of syndecan-1 in human hepatocellular carcinoma with high metastatic potential. Int J Cancer, 74(5), 482-491. http://dx.doi.org/10.1002/(SICI)1097-0215(19971021)74:5<482::AID-IJC2>3.0.CO;2-\#

Orosz, Z., \& Kopper, L. (2001). Syndecan-1 expression in different soft tissue tumours. Anticancer Res, 21(1B), 733-737.

O’Connell, F. P., Pinkus, J. L., \& Pinkus, G. S. (2004). CD138 (syndecan-1), a plasma cell marker: immunohistochemical profile in hematopoietic and nonhematopoietic neoplasms. Am J Clin Pathol, 121(2), 254-263. http://dx.doi.org/10.1309/617DWB5GNFWXHW4L

Sanderson, R. D., \& Borset, M. (2002). Syndecan-1 in B lymphoid malignancies. Ann Hematol, 81(3), 125-135. http://dx.doi.org/10.1007/s00277-002-0437-8

Shimada, K., Nakamura, M., De-Velasco, M. A., Tanaka, M., Ouji, Y., \& Konishi, N. (2009). Syndecan-1, a new target molecule involved in progression of androgen-independent prostate cancer. Cancer Sci, 100(7), 1248-1254. http://dx.doi.org/10.1111/j.1349-7006.2009.01174.x

Shimada, K., Nakamura, M., De-Velasco, M. A., Tanaka, M., Ouji, Y., Miyake, M., ... Konishi, N. (2010). Role of syndecan-1 (CD138) in cell survival of human urothelial carcinoma. Cancer Sci, 101(1), 155-160. http://dx.doi.org/10.1111/j.1349-7006.2009.01379.x

Teng, Y.H., Aquino, R.S., \& Park, P.W. (2012). Molecular functions of syndecan-1 in disease. Matrix Biol, 31(1), 3-16. http://dx.doi.org/10.1016/j.matbio.2011.10.001

Weiss, S. W., \& Rao, V. K. (1992). Well-differentiated liposarcoma (atypical lipoma) of deep soft tissue of the extremities, retroperitoneum, and miscellaneous sites. Am J Surg Pathol, 16(11), 1051-1058. http://dx.doi.org/10.1097/00000478-199211000-00003 
Zellweger, T., Ninck, C., Mirlacher, M., Annefeld, M., Glass, A. G., Gasser, T. C., ... Bubendorf, L. (2003). Tissue microarray analysis reveals prognostic significance of syndecan-1 expression in prostate cancer. Prostate, 55(1), 20-29. http://dx.doi.org/10.1002/pros.10209

\section{Copyrights}

Copyright for this article is retained by the author(s), with first publication rights granted to the journal.

This is an open-access article distributed under the terms and conditions of the Creative Commons Attribution license (http://creativecommons.org/licenses/by/3.0/). 